\title{
Ötiroid Tip 2 Diyabeti Olan Hastalarda HbA1c ve TSH Düzeylerinin Trigliserid Düzeylerine Etkisi
}

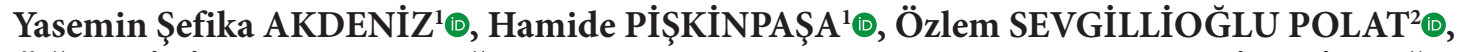

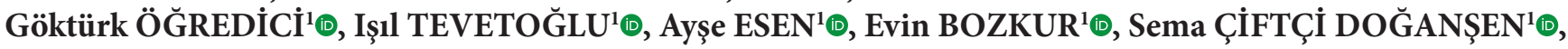 Yildız OKUTURLAR ${ }^{3}$, Meral MERT $^{1} \oplus$}

'Sağlık Bilimleri Üniversitesi, Bakırköy Dr Sadi Konuk Eğitim Araştırma Hastanesi, Endokrinoloji ve Metabolizma Hastalıkları Kliniği, İstanbul

${ }^{2}$ Sağlık Bilimleri Üniversitesi, Bakırköy Dr Sadi Konuk Eğitim Araştırma Hastanesi, Aile Hekimliği Kliniği, İstanbul

${ }^{3}$ Acıbadem Mehmet Ali Aydınlar Üniversitesi, Atakent Hastanesi, İç Hastalıkları Kliniği, İstanbul

Bu makaleye yapılacak atıf: Akdeniz YŞ, Pişkinpaşa H, Sevgillioğlu Polat Ö, Öğredici G, Tevetoğlu I, Esen A, Bozkur E, Çiftçi Doğanşen S, Okuturlar Y, Mert M. Ötiroid tip-2 diyabeti olan hastalarda HbAlc ve TSH düzeylerinin trigliserid düzeylerine etkisi. Türk Diyab Obez 2018;3: 119-124.

\begin{abstract}
ÖZET
Amaç: Diyabet tüm dünyada ve ülkemizde sıklığı giderek artan bir hastalıktır. Tip 2 diyabetli hastalarda dislipidemi, koroner arter hastalı̆̆ının (KAH) gelişiminde önemli risk artışına yol açmaktadır. Bu süreçte hipertrigliseridemi de LDL-HDL düzeyleri kadar önem arz etmektedir. HbAlc değeri yüksek olan kötü glisemik kontrollü diyabetik hastalarda komplikasyon riski artmış olup dislipidemi taraması ve tedavisi önemlidir. Normal tiroid fonksiyonlarındaki varyasyonların dislipidemi ve kardiyovasküler risk üzerine etkisi net bilinmemektedir. Çalışmamızda ötiroid Tip 2 diyabetes mellitus hastalarında trigliserid düzeyleri ile HbA1c ve TSH ilişkisini araştırdık.

Gereç ve Yöntemler: 19119 diyabet hastasının verileri retrospektif olarak taranarak incelendi. 4908 hasta verileri çalışmaya alınmaya uygun bulundu. HbA1c, TSH, glukoz ve trigliserid değerleri kaydedildi. Trigliserid değerlerine göre 4 gruba ayrılan hastalarda HbA1c ve TSH değerlerinin ilişkisi araştırıld.

Bulgular: HbAlc ve trigliserid düzeyleri arasında pozitif korelasyon, TSH ile negatif korelasyon saptandı.

Sonuç: Özellikle Tip 2 diyabet hastalarında tiroid fonksiyon testleri değerlendirilirken ötiroid olsalar dahi, glisemik regülasyon göstergelerinden $\mathrm{HbA1c}$ düzeyleri ile TSH düzeyleri arasındaki ilişki ve trigliserid düzeylerine etkileri göz önüne alınmalı, HbA1c değerleri düştükten sonraki seyirleri kontrol edilerek, tedavi ve takip yaklaşımları saptanmalıdır.
\end{abstract}

Anahtar Sözcükler: Tip 2 Diyabetes Mellitus, Trigliserid, TSH, HbAlc

\section{The Effect of HbA1c and TSH Levels on Triglyceride Levels in Euthyroid Patients with Type 2 Diabetes Mellitus}

\begin{abstract}
Aim: The prevalence of diabetes is increasing in our country and all over the world. Dyslipidemia has an important role in the development of coronary artery disease in patients with type-2 diabetes. The risk of complications is increased in diabetic patients with poor glycemic control and high HbAlc levels. Therefore dyslipidemia screening and treatment is important. The effect of variations in normal thyroid function on dyslipidemia and cardiovascular risk is not clear. So, in this study, we investigated the assosiation between HbAlc, TSH and triglyceride levels in euthyroid type 2 diabetic patients.
\end{abstract}

ORCID: Yasemin Şefika Akdeniz / 0000-0002-9740-6167, Hamide Pișkinpaşa / 0000-0002-8127-9543, Özlem Sevgillioğlu Polat / 0000-0002-7512-1283, Göktürk Öğredic / 0000-0001-7475-7426, Iș1l Tevetoğlu / 0000-0002-0559-9855, Ayşe Esen / 0000-0001-7129-4008, Evin Bozkur / 0000-0002-3799-2125, Sema Çiftçi Doğanşen / 0000-0002-0387-6562, Yıldız Okuturlar / 0000-0002-1994-0014, Meral Mert / 0000-0003-3431-0915 
Material and Methods: The data of 19119 diabetic patients were retrospectively analyzed and only 4908 patients' data were eligible to be included in the study. HbA1c, TSH, glucose and triglyceride values were recorded. Patients divided into 4 groups due to triglyceride levels in order to investigate assosiation between HbA1c, TSH levels and triglyceride levels in euthyroid, type 2 diabetic patients.

Results: There was a positive correlation between triglyceride and HbA1c levels and negative correlation between triglyceride and TSH levels.

Conclusion: Especially when evaluating thyroid function tests in patients with type-2 diabetes (even if they are euthyroid), the relationship between HbA1c levels and TSH levels and their effects on triglyceride levels should be considered. Treatment and followup approaches should be determined after HbAlc values are normalized.

Key Words: Type 2 Diabetes Mellitus, Triglyceride, TSH, HbA1c

\section{GİRİ̧}

Ülkemizde 20 yaş üzeri erişkinlerde yapılan Türkiye Diyabet Epidemiyolojisi Araştırması (TURDEP)-2 sonuçlarına göre diyabet prevalansı \%13.7’dur(1). Diyabette trigliserid (TG) yüksekliği, yüksek dansiteli lipoprotein (HDL) kolesterol düşüklüğü ve küçük yoğun düşük dansiteli lipoprotein (LDL) kolesterol oranı artışı ile karakterize aterojenik dislipidemi görülür. Diyabetli bireylerde koroner arter hastalığı riskinin artması lipoprotein anormallikleriyle açıklanmaktadır. Dislipidemi tanı anında veya prediyabetik dönemde dahi var olan bir durumdur. Diyabetik hastaların yaklaşık \%70-97'sinde bir veya daha fazla lipid bozukluğu bildirilmiştir (2). İnsülin direncinin varlığında, hormonduyarlı lipazın inhibisyonunun azalması sonucunda, adipoz dokudan karaciğere serbest yağ asidi akışı artar. İnsulin karaciğer apolipoprotein üretimini etkiler, lipoprotein lipaz (LpL) enzim aktivitesini düzenler. Bunlara bağlı olarak diyabetik dislipidemi gelişir (3-4).

Trigliserid düzeylerinin $>150 \quad \mathrm{mg} / \mathrm{dl}$ olması hipertrigliseridemi (HTG) olarak tanımlanır. TG düzeyleri 150-499 mg/dl arasındaysa hafif HTG, 500$880 \mathrm{mg} / \mathrm{dl}$ arasindaysa orta HTG ve > $880 \mathrm{mg} / \mathrm{dl}$ olması durumunda şiddetli HTG varlığından söz edilir (5). Tip 2 diyabet ve hipotiroidi yüksek TG düzeyleri ile ilişkili olduğu gösterilmiş iki hastalıktır. HTG kardiyovasküler morbidite ve mortalitenin bağımsız belirleyicisidir ayrıca hipertrigliseridemi olgularında yağlı karaciğer hastalığı ve pankreatit riskinde artış söz konusudur(6).

Diyabetik hastalarda diyabetik olmayan bireylerle karşılaştırıldığında daha yüksek oranda aterojenik lipid profili görülür bu sebeple dislipideminin eşlik ettiği diyabetiklerde kardiyovasküler mortalite daha yüksektir. Diyabetik hastalarda lipid düzeylerinin hedef değerlere çekilmesiilekardiyovasküler mortalite vekomplikasyonların azaldığı gösterilmiştir (7).

Hipotiroidiye sıklıkla artmış kardiyovasküler hastalık riski ile ilişkili serum lipid konsantrasyonları eşlik eder(8-9). Yüksek tiroid stimule edici hormon (TSH) ile birlikte referans aralığındaki serbest T4 ve T3 hormonları ile karakterize subklinik hipotiroidizm, özellikle TSH 10 mU/l'den yüksekse, istenmeyen serum lipidleri ile de ilişkili olabilir (10). Ayrıca, subklinik olarak hipotiroidik bireylerin tiroksin tedavisi toplam serum kolesterolünü ve LDL kolesterolü azaltabilir (11). Klinik olarak ötiroid olan hastalarda yapılan çalışmalarda TSH düzeyi ile LDL düzeyleri arasında doğru orantılı ilişki olduğu gösterilmiştir (12).

Çalışmamızda ötiroid Tip 2 diabetes mellitus hastalarında TG düzeyleri ile Hemoglobin Alc (HbAlc) ve TSH arasındaki ilişkiyi araştırdık.

\section{GEREÇ ve YÖNTEMLER}

Sağlık Bilimleri Üniversitesi, Bakırköy Dr Sadi Konuk Eğitim ve Araştırma Hastanesine son beş yıl içerisinde diyabet tanısı ile başvuran 19119 hastanın dosyası retrospektif olarak tarandı. Etik kurul onayı alındı. Mükerrer hasta kayıtları, aynı gün içerisinde glukoz, HbA1c, TSH ve lipid parametreleri kayıtlı olmayan hastalar ve Tip 1 diyabet tanılı hastalar (500 olgu) çalışmaya dahil edilmedi. Hipotiroidi ve hipertiroidinin lipid parametreleri üzerine olan etkisi nedeni ile TSH değerleri hastanemiz referans aralığında

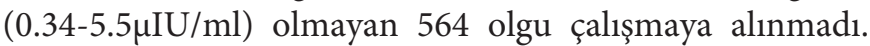
Çalışmaya alınma kriterlerini karşılayan 4908 Tip 2 diyabetik olgu dosyası retrospektif olarak incelendi. Hastaların yaşı, cinsiyeti, glukoz, HbA1c, TG ve TSH düzeyleri kaydedildi. Hastalar Türkiye Endokrinoloji ve Metabolizma Derneği 2018 yılı lipid kılavuzu (5) referans alınarak TG düzeylerine göre normal, hafif, orta ve ağır HTG olarak gruplandırıldı. TG $<150$ mg/dl olan 2369 olgu [1463 kadın (\%61,8), 906 erkek(\%38,2)] grup1, $150 \mathrm{mg} / \mathrm{dl} \leq \mathrm{TG}<500 \mathrm{mg} / \mathrm{dl}$ olan 2384 olgu [1479 kadin (\%62,0), $905 \operatorname{erkek}(\% 38,0)]$ grup 2, 500 $\mathrm{mg} / \mathrm{dl} \leq \mathrm{TG}<880 \mathrm{mg} / \mathrm{dl}$ olan 111 olgu [54 kadın $(\% 48,6)$, 57 erkek $(\% 51,4)]$ grup $3, \mathrm{TG} \geq 880 \mathrm{mg} / \mathrm{dl}$ olan 44 olgu [20 kadin (\%45,5), 24 erkek (\%54,5)] grup 4 olarak ayrıldı.

Tip 2 diyabetli, ötiroid hastalarda TSH ve HbA1c düzeylerinin trigliserid düzeylerine olan etkileri araştırıldı.

HbA1c düzeyleri HPLC yöntemi ile Arkray-Adams HA$8180 \mathrm{~V}$, Mineapolis USA, cihazında çalışıldı. Glukoz heksodimeraz yöntemi ve trigliserid düzeyleri ise 
kalorimetrik yöntem ile A BECKMAN COULTER A4 5800 Brea, CA,USA cihazında çalışıldı. TSH düzeyleri kemiluminesans yöntemi ile BECKMAN COULTER Unicel DxI 800, Brea, CA,92821 cihazında çalışıldı. Diğer laboratuvar tetkiklerinde spektrofotometrik yöntemle otoanalizörler kullanıldı.

\section{İstatistiksel Analiz}

Verilerin istatistiksel değerlendirilmesi için SPSS for Windows 23.00 paket programı kullanıldı. Parametrik veriler ortalama \pm standart sapma (SS) ile gösterildi. Normal dağılıma uygunluk Kolmogorov Smirnov testi ile değerlendirilmiştir. Gruplar arasındaki farklılıklar iki grubun karşılaştırılması gerekli olduğunda karşılaştırmalar 'Independent Sample-T Test' veya Mann-Whitney U testi, ikiden fazla grubun karşılaştırılması gerektiğinde Kruskal Wallis testi ile araştırılmıştır. Gruplar arası korelasyon değerlendirmeleri 'Spearman Testi' kullanılarak yapıldı.
0.05 'in altındaki p değeri istatistiksel olarak anlamlı kabul edildi.

\section{BULGULAR}

Çalışmamıza toplam 4908 hasta alındı. Trigliserid değerlerine göre dört ayrı gruba ayrılan hastalara ait yaş, HbA1c, kolesterol, glukoz, TSH, sT4,TG ve HDL değerleri Tablo 1'de özetlenmiştir.

Tablo 2'de gruplar arası karşılaştırma sonuçları, Tablo 3'te tüm hasta grubu için korelasyon sonuçları görülmektedir. Tablo 4'te ise gruplardaki ilişki analizi sonuçları mevcuttur.

Trigliserid değeri $500 \mathrm{mg} / \mathrm{dl}$ altı olanlarda ortalama HbA1c $7.9 \pm 1.8$ iken $\geq 500 \mathrm{mg} / \mathrm{dl}$ olanlarda ortalama HbA1c $10.2 \pm 2.1$ olduğu görüldü.

Ötiroid Tip 2 diyabetli hasta grubunda TG değeri 500 mg/dl altı ve üzeri olan hastalarda TSH değerleri açısından anlamlı fark yoktu ( $\mathrm{p}=0.446)$. Tüm gruplar arasında TSH düzeyleri

Tablo 1: Hastaların deskriptif verileri

\begin{tabular}{lcccccc}
\hline & Grup 1 n=2369 & Grup 2 n=2384 & Grup 3 n=111 & Grup 4 n= 44 & Total n=4908 & peğeri \\
\cline { 2 - 6 } & Ort \pm SS & Ort \pm SS & Ort \pm SS & Ort \pm SS & Ort \pm SS & \\
\hline Yaş (yll) & $57,67 \pm 11.95$ & $56,66 \pm 10,89$ & $52,48 \pm 9,63$ & $47.75 \pm 8.17$ & $56,98 \pm 11,43$ & $\mathbf{0 , 0 0 0 1}$ \\
\hline A1c (\%) & $8,25 \pm 1,73$ & $8,72 \pm 1,98$ & $9,70 \pm 2,09$ & $10,77 \pm 2.11$ & $8,54 \pm 1,90$ & $\mathbf{0 , 0 0 0 1}$ \\
\hline Glukoz (mg/dl) & $175,41 \pm 69,95$ & $197,90 \pm 81,44$ & $239,34 \pm 89,51$ & $288,29 \pm 89.16$ & $188,79 \pm 78,13$ & $\mathbf{0 , 0 0 0 1}$ \\
\hline Kolesterol & $191,29 \pm 43,36$ & $220,62 \pm 44,47$ & $260,39 \pm 53,44$ & $335,04 \pm 151,06$ & $208,47 \pm 50,57$ & $\mathbf{0 , 0 0 0 1}$ \\
\hline TG (mg/dl) & $106,65 \pm 27,56$ & $236,42 \pm 76,72$ & $605,89 \pm 98,57$ & $1305,20 \pm 1249,67$ & $191,72 \pm 191,28$ & $\mathbf{0 , 0 0 0 1}$ \\
\hline HDL (mg/dl) & $52,45 \pm 14,51$ & $42,43 \pm 10,50$ & $33,86 \pm 8,19$ & $29,13 \pm 7,04$ & $46,95 \pm 13,72$ & $\mathbf{0 , 0 0 0 1}$ \\
\hline LDL (mg/dl) & $118,43 \pm 36,67$ & $133,49 \pm 40,15$ & $173,02 \pm 55,82$ & $100,61 \pm 49,88$ & $125,76 \pm 39,42$ & $\mathbf{0 , 0 0 0 1}$ \\
\hline TSH (uIU/ml) & $2,02 \pm 1,14$ & $2,06 \pm 1,147$ & $2,05 \pm 1,17$ & $2,31 \pm 1,19$ & $2,04 \pm 1,14$ & 0,147 \\
\hline sT4 (pmol/L) & $1,31 \pm 0,2$ & $1,28 \pm 0,19$ & $1,30 \pm 0,20$ & $1,22 \pm 0,23$ & $1,30 \pm 0,19$ & $\mathbf{0 , 0 0 2}$ \\
\hline
\end{tabular}

Ort: Ortalama, SS: Standart sapma, A1c: Glikozillenmiș Hemoglobin, TG: Trigliserid, HDL: Yüksek molekül ağırlıklı kolesterol, LDL: Düșük molekül ağırlıklı kolesterol, TSH: Tiroid stimulülan hormon, sT4: Serbest T4

Tablo 2: Gruplar arası karşılaştırma

\begin{tabular}{lccccc}
\hline & $\begin{array}{c}\text { Grup 1\&2 } \\
\text { p değeri }\end{array}$ & $\begin{array}{c}\text { Grup 1\&3 } \\
\text { p değeri }\end{array}$ & $\begin{array}{c}\text { Grup 1\&4 } \\
\text { p değeri }\end{array}$ & $\begin{array}{c}\text { Grup 2\&3 } \\
\text { p değeri }\end{array}$ & $\begin{array}{c}\text { Grup 2\&4 } \\
\text { pdeğeri }\end{array}$ \\
\hline Yaş (yll) & 0,0002 & 0,0000 & 0,0000 & 0,0001 & 0,0001 \\
\hline A1c (\%) & 0,0001 & 0,0001 & 0,0001 & 0,0001 & 0,0001 \\
\hline Glukoz (mg/dl) & 0,0001 & 0,0001 & 0,0001 & 0,0001 & 0,0001 \\
\hline Kolesterol & 0,0001 & 0,0001 & 0,0001 & 0,0001 & 0,0001 \\
\hline TG (mg/dl) & 0,0001 & 0,0001 & 0,0001 & 0,0001 & 0,0001 \\
\hline HDL (mg/dl) & 0,0001 & 0,0001 & 0,0001 & 0,0001 & 0,0001 \\
\hline LDL (mg/dl) & 0,0001 & 0,0002 & 0,001 & 0,005 & 0,0001 \\
\hline sT4 (pmol/L) & 0,001 & 0,841 & 0,036 & 0,240 & 0,131 \\
\hline Alc:
\end{tabular}

A1c: Glikozillenmiş Hemoglobin, TG: Trigliserid, HDL: Yüksek molekül ağırlıklı kolesterol, LDL: Düşük molekül ağırlıklı kolesterol, sT4: Serbest T4 
Tablo 3: Tüm hastalarda korelasyon analizi

\begin{tabular}{lcclcc}
\hline Alc & r değeri & p değeri & TSH & r değeri & p değeri \\
\hline Yaş & $-0,119$ & 0,0001 & Yaş & 0,023 & 0,1 \\
\hline Glukoz & 0,746 & 0,0001 & Alc & $-0,058$ & 0,0001 \\
\hline Kolesterol & 0,064 & 0,0001 & Glukoz & $-0,065$ & 0,0001 \\
\hline TG & 0,184 & 0,0001 & Kolesterol & 0,054 & 0,0001 \\
\hline HDL & $-0,162$ & 0,0001 & TG & 0,032 & 0,026 \\
\hline LDL & 0,021 & 0,1441 & HDL & 0,036 & 0,014 \\
\hline TSH & $-0,058$ & 0,0001 & LDL & 0,037 & 0,012 \\
\hline sT4 & 0,13 & 0,0001 & sT4 & $-0,182$ & 0,0001 \\
\hline
\end{tabular}

A1c: Glikozillenmiş Hemoglobin, TG: Trigliserid, HDL: Yüksek molekül ağırlıklı kolesterol, LDL: Düşük molekül ağırlıklı kolesterol, TSH: Tiroid stimulülan hormon, sT4: Serbest T4

Tablo 4: Her grubun kendi içerisindeki TSH ve A1c düzeylerinin diğer parametrelerle olan ilişkisi

\begin{tabular}{|c|c|c|c|c|c|c|c|c|c|c|c|c|c|c|c|c|}
\hline & \multicolumn{4}{|c|}{ Grup $1 \mathrm{n}=2369$} & \multicolumn{4}{|c|}{ Grup 2 n=2384 } & \multicolumn{4}{|c|}{ Grup3 n=111 } & \multicolumn{4}{|c|}{ Grup 4 n=44 } \\
\hline & \multicolumn{2}{|c|}{ TSH } & \multicolumn{2}{|c|}{ A1c } & \multicolumn{2}{|c|}{ TSH } & \multicolumn{2}{|c|}{ A1c } & \multicolumn{2}{|c|}{ TSH } & \multicolumn{2}{|c|}{ A1c } & \multicolumn{2}{|c|}{ TSH } & \multicolumn{2}{|c|}{ A1c } \\
\hline & $\begin{array}{c}\mathbf{r} \\
\text { değeri } \\
\end{array}$ & $\begin{array}{c}\mathbf{p} \\
\text { değeri }\end{array}$ & $\begin{array}{c}\mathbf{r} \\
\text { değeri } \\
\end{array}$ & $\begin{array}{c}\mathbf{p} \\
\text { değeri }\end{array}$ & $\begin{array}{c}\mathbf{r} \\
\text { değeri } \\
\end{array}$ & $\begin{array}{c}\mathbf{p} \\
\text { değeri }\end{array}$ & $\begin{array}{c}\mathbf{r} \\
\text { değeri }\end{array}$ & $\begin{array}{c}\mathbf{p} \\
\text { değeri }\end{array}$ & $\begin{array}{c}\mathbf{r} \\
\text { değeri } \\
\end{array}$ & $\begin{array}{c}\mathbf{p} \\
\text { değeri }\end{array}$ & $\begin{array}{c}\mathbf{r} \\
\text { değeri } \\
\end{array}$ & $\begin{array}{c}\mathbf{p} \\
\text { değeri }\end{array}$ & $\begin{array}{c}\mathbf{r} \\
\text { değeri }\end{array}$ & $\begin{array}{c}\mathbf{p} \\
\text { değeri }\end{array}$ & $\begin{array}{c}\mathbf{r} \\
\text { değeri } \\
\end{array}$ & $\begin{array}{c}\mathbf{p} \\
\text { değeri }\end{array}$ \\
\hline TSH & & & $-0,095$ & 0,0001 & & & $-0,04$ & 0,054 & & & 0,127 & 0,184 & & & $-0,02$ & 0,897 \\
\hline Yaş & 0,001 & 0,948 & $-0,135$ & 0,0001 & 0,059 & 0,004 & $-0,072$ & 0,0001 & $-0,058$ & 0,546 & 0,002 & 0,984 & $-0,273$ & 0,073 & 0,08 & 0,607 \\
\hline A1c & $-0,095$ & 0,0001 & & & $-0,04$ & 0,054 & & & 0,127 & 0,184 & & & $-0,02$ & 0,897 & & \\
\hline Kolesterol & 0,025 & 0,232 & $-0,023$ & 0,291 & 0,066 & 0,002 & 0,031 & 0,138 & 0,141 & 0,154 & 0,055 & 0,582 & 0,084 & 0,598 & 0,264 & 0,091 \\
\hline TG & 0,021 & 0,311 & 0,059 & 0,004 & 0,018 & 0,392 & 0,134 & 0,0001 & 0,045 & 0,638 & $-0,009$ & 0,924 & $-0,022$ & 0,888 & 0,118 & 0,445 \\
\hline HDL & 0,052 & 0,015 & $-0,113$ & 0,0001 & 0,054 & 0,011 & $-0,096$ & 0,0001 & $-0,015$ & 0,882 & $-0,03$ & 0,764 & 0,042 & 0,79 & $-0,119$ & 0,447 \\
\hline $\mathrm{LDL}$ & 0,011 & 0,582 & 0,001 & 0,945 & 0,058 & 0,006 & 0,012 & 0,571 & $-0,228$ & 0,453 & $-0,082$ & 0,789 & 0,098 & 0,569 & 0,196 & 0,251 \\
\hline
\end{tabular}

A1c: Glikozillenmiş Hemoglobin, TG: Trigliserid, HDL: Yüksek molekül ağırlıklı kolesterol, LDL: Düşük molekül ağırlıklı kolesterol, TSH: Tiroid stimulülan hormon, sT4: Serbest T4

açısından istatistiksel olarak anlamlı fark görülemedi. TG değeri $150 \mathrm{mg} / \mathrm{dl}$ altında ve üzerinde olan hastalar karşılaştırıldığında TG düzeyi ile TSH değerleri arasında istatistiksel olarak anlamlı fark görülemedi.

HbAlc ve TG düzeyleri arasinda grup 1 ve grup 2 olan hastalarda pozitif ilişki görüldü. HbA1c ve TSH değerleri arasında negatif korelasyon olduğu görüldü.

\section{TARTIŞMA}

Hemoglobin Alc, hemoglobinin yavaş ve enzimatik olmayan glikozillenmesi sonucu oluşan bir belirteçtir. Uzun dönem glisemik kontrolü değerlendirmek için kullanılır. Ortalama glukoz düzeyini gösteren bir belirteç olarak $\mathrm{HbAlc}$ diyabetik hastalarda komplikasyon gelişme riskini öngördürür(13).

Tip 2 diyabet erken başlangıçlı ve şiddetli ateroskleroza sekonder olarak kardiyovasküler olaylar açısından belirgin bir risk artışı ile birliktedir. Tip 2 diyabetli hastalarda kardiyovasküler hastalıkların 2-4 kat arttığı ve tüm kardiyovasküler ölümlerin dörtte üçünden sorumlu olduğu bilinmektedir (14). NCEP-ATP III kllavuzu diyabeti koroner kalp hastalığı risk eşdeğeri olarak kabul etmektedir (15).

Tip 2 diabetes mellituslu hastalarda, dislipideminin erken saptanması ve tedavisinin, aterosklerotik kalp-damar hastalıkları ve inme riskini azalttığı gösterilmiştir. Bu nedenle $\mathrm{HbAlc}$ değeri yüksek olan kötü glisemik kontrollü diyabetik hastalarda, dislipidemi erkenden taranıp tedavi edilmeye başlanmalıdır.

Khan HA ve ark. 2006 yilında Riyad'daki Armed Forces Hastanesi diyabet kliniğinde yaklaşık 2220 (1148 erkek, 1072 kadın) tip 2 diyabet hastasını HbA1c düzeylerine göre $\% 6$ 'nın altında olanlar, \%6 ile \%9 arasında ve \%9'un üstünde olanlar diye üç gruba ayırmışlar ve HbAlc ile trigliserid 
arasında doğru, HDL kolesterol arasında ters bir ilişki saptamışlardır. LDL ve total kolesterol düzeylerinde anlamlı değişiklikler saptamamışlardır (16). Mahato ve ark. Nepal'de yaptıkları çalışmada $\mathrm{HbA1c} \% 7$ 'den büyük olan hastalarda; total kolesterol, LDL kolesterol ve trigliseridin $\mathrm{HbAlc}$ $\% 7$ 'den küçük olan hastalara göre daha yüksek olduğunu göstermişlerdir (17). İstanbul Eğitim ve Araştırma Hastanesi Diyabet Polikliniği'ne başvuran hastalar arasından seçilen 165 tip 2 diyabet hasta üzerinde yapılan bir çalışmada HbAlc değeri 7,5 üzerinde olan hastalarda, totalkolesterol, trigliserid ve LDL değerleri $\mathrm{HbAlc}$ düzeyi $<7,5$ olan gruba göre anlamlı derecede daha yüksek saptanmıştır (18).

$\mathrm{Bu}$ çalısmalarda hastaların lipid değerleri HbAlc değerlerine odaklı yaklaşım ile değerlendirilmiştir. Hastaların TG değerlerine göre gruplara ayrıldığı çalışmamızda, TG düzeyleri $\geq 500 \mathrm{mg} / \mathrm{dl}$ olan grup 1 ve 2 hastalarında $\mathrm{HbAlc}$ ile TG düzeyleri arasında pozitif korelasyon saptadık. Daha yüksek trigliserid değerlerine sahip hastalarda ise $\mathrm{HbAlc}$ ve TG düzeyleri arasında ilişki saptanmamıştır. Bu gruplardaki hasta sayısının ilk iki gruba göre göreceli az olması etken olabilir.

Hem yüksek HbAlc hem de dislipidemi kardiyovasküler hastalık için bağımsız risk faktörleridir. Bu iki risk faktörünün birlikte bulunduğu diyabetik hastalar KVH için çok yüksek riskli bir grup olarak düşünülebilir. Glisemik kontrolün geliştirilmesi diyabetiklerde kardiyovasküler olay riskini önemli ölçüde azaltabilir (19).

Diyabet hastalarında tiroid hastalığı yaygın olarak görülür. Tip 2 diyabetiklerde tiroid bozukluğu prevalansı daha yüksektir ve yaşla artar. Tip 1 diyabetlilerde altta yatan otoimmunite ile daha fazla ilişkilidir. $\mathrm{Bu}$ bulgu diyabetli kadınlarda daha yaygındır. En sık görülen tiroid bozukluğu hipotiroididir. Kontrolsüz diyabet hastalarında tiroid bozukluğunun diyabetle ilişkisi daha sıktır. Tiroid hastalıkları glikoz ile hemoglobin seviyelerini de etkiler. $\mathrm{Bu}$ nedenle, diyabetik hastalarda tiroid hastalığının glisemik kontrolü bozarak diyabetik tabloyu ağırlaştırabileceği gibi diyabetik durumun tiroid hastalığının semptomlarını maskeleyebileceği hatırlanmalıdır (20).

Insülin ve tiroid hormonları, hücresel metabolizmayla yakından ilişkilidir bu hormonların herhangi birinin artışı veya eksikliği, diğerinin fonksiyonunun bozulmasına yol açar. Yüksek seviyelerdeki tiroid hormonu diyabetojeniktir (21). Tiroid hormon replasman1, HbAlc seviyesinde azalma ile ilişkilidir. Bu azalma glikoz seviyesindeki değişikliklerden ziyade artmış eritropoezden etkilenir (22).

Klinik olarak normal tiroid fonksiyonunu gösteren TSH düzeylerinin, serum lipitleri ile ilişkili olarak kardiyovasküler sağlık üzerinde uzun süreli zararlı etkileri olabilir. Bununla birlikte, bağlantı orta düzeydedir ve normal tiroid fonksiyonlarındaki varyasyonların kardiyovasküler risk üzerine etkisi daha fazla çalışma ile desteklenmelidir.

Ötiroid Tip 2 diyabet hastalarının alındığı çalışmamızda tüm hasta gruplarında TSH ile TG arasında ilişki saptanmazken, HbAlc ile TSH arasında negatif korelasyon saptandi. Subgruplar arasında ise ilişki saptanmadi. TG değeri çok yüksek olan grup 3 ve 4'te hasta sayısının göreceli az olması nedeniyle bu sonuç elde edilmiş olabilir. Tüm hasta grubunda HbA1c ile TSH arasındaki negatif ilişki saptanması literatür ile uyumludur. Çalışmamızda TG düzeyi ve TSH değerleri ilişkisini incelediğimizde, ötiroid Tip 2 diyabetli hasta grubunda TG $\leq 500 \mathrm{mg} / \mathrm{dl}$ ve TG $>500$ $\mathrm{mg} / \mathrm{dl}$ olan hastalarda TSH değerleri açısından anlamlı fark saptanmadı $(p=0.446)$. Ayrıca tüm gruplar arasında da TSH düzeyleri açısından istatistiksel olarak anlamlı fark görülemedi. TG değeri $\leq 150 \mathrm{mg} / \mathrm{dl}$ olan normal lipid profiline sahip hastalar ve TG $>150 \mathrm{mg} / \mathrm{dl}$ olan dislipidemik hastalar karşlaştırıldığında TG düzeyi ile TSH değerleri arasında istatistiksel olarak anlamlı fark görülemedi. Hasta grupları TSH, TG ve HbAlc arasında, farklılık ve ilişki açısından değerlendirildiğinde, TG düzeylerinden ziyade HbAlc düzeyi ile TSH arasındaki negatif ilişki anlamlı görünmektedir. HbAlc ile TG değerleri arasındaki ilişki, literatüre uygun olarak, bizim çalışmamızda da pozitif idi. Tip 2 diyabet hastalarında TFT değerlendirilirken, ötiroid olsalar dahi, glisemik regülasyon göstergelerinden HbAlc düzeyleri ile TSH düzeyleri arasındaki ilişki ve TG düzeylerine etkileri göz önüne alınmalı, diyabet regüle edilerek $\mathrm{HbA} 1 \mathrm{c}$ değerleri düştükten sonraki seyirleri kontrol edilerek, tedavi ve takip yaklaşımları saptanmalıdır.

Çalışmamızın kısıtlılıkları arasında, retrospektif olarak yapılması nedeni ile hastaların vücut kitle indeksleri ve diyet, egzersiz alışkanlıklarının bilinmemesi, hastaların statin veya fibrat benzeri lipid düşürücü tedavi alıp almadıkları sorgulanamamış olması yer almaktadır.

Çıkar Çatışması: Yazarlar olarak herhangi bir çıkar çatışmamız olmadığını beyan ederiz.

\section{KAYNAKLAR}

1. Satman I, Omer B, et al. Twelve-year trends in the prevalence and risk factors of diabetes and prediabetes in Turkish adults. Eur J Epidemiol. 2013;28:169-180.

2. American Diabetes Association. Dyslipidemia Management in Adults With Diabetes. Diabetes Care. 2004;27:68-71.

3. Goldberg IJ. Lipoprotein lipase and lipolysis: Central roles in lipoprotein metabolism and atherogenesis. J Lipid Res. 1996; 37:693-707.

4. Tavangar K, Murata Y, et al. Regulation of lipoprotein lipase in the diabetic rat. J Clin Invest. 1992;90:1672-1678. 
5. Türkiye Endokrinoloji ve Metabolizma Derneği Dislipidemi Tanı ve Tedavi Kılavuzu. 2018;85-86. (http://www.temd.org. tr/admin/uploads/tbl_gruplar/20180525144116-2018-0525tbl_gruplar144111.pdf, Erişim Tarihi 18.11.2018)

6. Rosenson RS, Davidson MH, et al. Genetics and Causality of Triglyceride-Rich Lipoproteins in Atherosclerotic Cardiovascular Disease. JAC. 2014;64(23):2525-2540.

7. Windler E. What is the consequence of an abnormal lipid profile in patients with type 2 diabetes or the metabolic syndrome? Atheroscler Suppl. 2005;6:11-14.

8. Duntas LH. Thyroid disease and lipids. Thyroid. 2002;12:287293.

9. 9.Canaris GJ, Manowitz NR et al The Colorado thyroid disease prevalence study. Archives of Internal Medicine. 2000;160: 526-534.

10. 10.Surks MI, Ortiz E et al.Subclinical thyroid disease: Scientific review and guidelines for diagnosis and management. Journal of the American Medical Association. 2004;291:228-238.

11. Iqbal A, Jorde $\mathrm{R}$ et al.Serum lipid levels in relation to serum thyroid-stimulating hormone and the effect of thyroxine treatment on serum lipid levels in subjects with subclinical hypothyroidism: The Tromso Study. Journal of Internal Medicine. 2006;260:53-61.

12. Bakker SJ, ter Maaten JC, et al. The relationship between thyrotropin and low density lipoprotein cholesterol is modified by insulin sensitivity in healthy euthyroid subjects. Journal of Clinical Endocrinology and Metabolism. 2001;86: 1206-1211.

13. Glycosylaed Haemoglobin, HbA1C. Erişim: (http://www. clinlabnavigator.com/hemoglobin-alc.html, Accessed Date: 18.11.2018)
14. Haffner SM, Lehto S et al. Mortality from coronary heart disease in subjects with type 2 diabetes and in nondiabetic subjects with and without prior myocardial infarction. N Engl J Med. 1998;339:229-234.

15. (NCEP) Expert Panel on Detection, Evaluation and Treatment of High Blood Cholesterol in Adults (Adult Treatment Panel III). JAMA. 2001;285:2486-2497.

16. Khan HA, Sobki SH et al. Association between glycaemic control and serum lipids profile in type 2 diabetic patients: HbA1c predicts dyslipidaemia. Clin Exp Med. 2007;7:24-29.

17. Mahato RV, Gyawali P, et al. Association between glycaemic control and serum lipid profile in type 2 diabetic patients: Glycated haemoglobin as a dual biomarker. Biomed Res. 2011; 22:375-380.

18. Ebru Özdoğan, Osman Özdoğan et al. Tip 2 Diyabet Hastalarında Kan Lipid Düzeylerinin Hba1c ve Obezite ile İlişkisi şişli etfal hastanesi tıp bülteni. 2015;49;4:248-254.

19. Selvin E, Wattanakit K et al. HbAlc and peripheral arterial disease in diabetes: The Atherosclerosis Risk in Communities study. Diabetes Care. 2006;29:877-882.

20. Johnson JL. Diabetes control in thyroid disease. Diabetes Spectr. 2006;19:148-153.

21. Granner DK. Thyroid hormones. In Murray R.K, Granner DK, Mayes PA, Rodwell VW.ed. Harper's Biochemistry, 25th ed. London, Prentice-Hall international Inc.2000;533-538.

22. Kim MK, Kwon HS, et al. Effects of thyroid hormone on A1C and glycated albumin levels in nondiabetic subjects with overt hypothyroidism. Diabetes Care. 2010;33:2546-2548. 